\title{
Role of cranial computed tomography in human immunodeficiency virus-positive patients with generalised seizures
}

\begin{tabular}{|c|c|}
\hline \multicolumn{2}{|c|}{$\begin{array}{l}\text { Authors: } \\
\text { Chris van Zyl }{ }^{1} \\
\text { Delmé Hurter } \\
\text { Vishesh Sood } \\
\text { Lizanne Koning } \\
\text { Lizan }\end{array}$} \\
\hline \multicolumn{2}{|c|}{$\begin{array}{l}\text { Affiliations: } \\
\text { }{ }^{\text {Department of Clinical }} \\
\text { Imaging Sciences, University } \\
\text { of the Free State, } \\
\text { South Africa }\end{array}$} \\
\hline \multicolumn{2}{|c|}{$\begin{array}{l}\text { 2Department of Radiology, } \\
\text { Kimberley Hospital Complex, } \\
\text { University of the Free State, } \\
\text { South Africa }\end{array}$} \\
\hline \multicolumn{2}{|c|}{$\begin{array}{l}{ }^{3} \text { Emergency Centre, } \\
\text { Kimberley Hospital Complex, } \\
\text { University of the Free State, } \\
\text { South Africa }\end{array}$} \\
\hline \multicolumn{2}{|c|}{$\begin{array}{l}\text { Corresponding author: } \\
\text { Chris van Zyl, } \\
\text { chrisjvanzyl@gmail.com }\end{array}$} \\
\hline $\begin{array}{l}\text { Dates: } \\
\text { Received: } 06 \\
\text { Accepted: } 01 \\
\text { Published: } 14\end{array}$ & $\begin{array}{l}\text { ec. } 2015 \\
\text { pr. } 2016 \\
\text { une } 2016\end{array}$ \\
\hline \multicolumn{2}{|c|}{$\begin{array}{l}\text { How to cite this article: } \\
\text { Van Zyl C, Hurter D, Sood V, } \\
\text { Koning L. Role of cranial } \\
\text { computed tomography in } \\
\text { human immunodeficiency } \\
\text { virus-positive patients with } \\
\text { generalised seizures S Afr J } \\
\text { Rad. 2016;20(1), a965. } \\
\text { http://dx.doi.org/10.4102/ } \\
\text { sajr.v20i1.965 }\end{array}$} \\
\hline \multicolumn{2}{|c|}{$\begin{array}{l}\text { Copyright: } \\
\text { (C) 2016. The Authors. } \\
\text { Licensee: AOSIS. This work } \\
\text { is licensed under the } \\
\text { Creative Commons } \\
\text { Attribution License. }\end{array}$} \\
\hline \multicolumn{2}{|l|}{ Read online: } \\
\hline 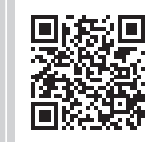 & $\begin{array}{l}\text { Scan this QR } \\
\text { code with your } \\
\text { smart phone or } \\
\text { mobile device } \\
\text { to read online. }\end{array}$ \\
\hline
\end{tabular}

Background: Emergency neuroimaging of human immunodeficiency virus (HIV)-positive patients with generalised new onset seizures (NOS) and a normal post-ictal neurological examination remains controversial, with the general impression being that emergency imaging is necessary because immunosuppression may blur clinical indicators of acute intracranial pathology. The objectives of our study were to establish whether cranial computed tomography (CT) affects the emergency management of HIV-positive patients with generalised NOS and a normal post-ictal neurological examination.

Method: We conducted a prospective descriptive observational study. Consecutive HIVpositive patients of 18 years and older, who presented to the Kimberley Hospital Complex's Emergency Department within 24 hours of their first generalised seizures and who had undergone normal post-ictal neurological examinations, were included. Emergency CT results as well as CD4-count levels were evaluated.

Results: A total of 25 HIV-positive patients were included in the study. The results of cranial CT brought about a change in emergency care management in $12 \%$ of patients, all of them with CD4 counts below 200 cells $/ \mathrm{mm}^{3}$.

Conclusion: We suggest that emergency cranial CT be performed on all HIV-positive patients presenting with generalised NOS and a normal post-ictal neurological examination, particularly if the CD4 count is below 200 cells $/ \mathrm{mm}^{3}$.

\section{Introduction}

Emergency neuroimaging of new onset seizures (NOS) in patients infected with the human immunodeficiency virus (HIV) remains controversial, with the general impression being that emergency imaging is necessary because immunosuppression may blur clinical indicators of acute intracranial pathology. ${ }^{1,2}$

In our institution, which is a centre with a significant radiological burden (serving a population of 1.2 million people), we currently use the Kimberley Hospital Rule for urgent computed tomography $(\mathrm{CT})$ of the brain in a resource-limited environment, ${ }^{3}$ which includes emergency scanning of all patients with focal seizures. However, no clear guideline exists for HIV-infected patients presenting with generalised seizures and a normal post-ictal neurological examination, and therefore it is an area requiring further investigation.

\section{Objective}

The aim of our study was to establish whether cranial CT has an influence on the emergency management, and ultimately expedites the treatment, of HIV-positive patients with generalised NOS and a normal post-ictal neurological examination.

\section{Literature review}

Review of the literature produces conflicting findings, with some authors advocating emergency neuroimaging on all HIV-positive patients, and some reliance on clinical signs as indications for emergency neuroimaging. Furthermore, few authors differentiate between generalised seizures and focal seizures.

Barber et al. noticed that the majority of urgent cranial CT requests for HIV-infected patients at their hospital was motivated by clinicians believing that immune-compromised patients might 
have focal intracranial sepsis without the usual clinical signs. Barber et al. gained the impression that many of these scans were normal, and they investigated whether clinical signs were helpful in pointing to patients who harboured intracranial pathology. The authors divided their study sample into two groups: HIV-positive patients, and patients with acquired immune deficiency syndrome (AIDS). In the HIV-positive group, no patient had treatable intracranial pathology without focal neurological signs. In the AIDS group, the majority of patients with treatable intracranial disease presented with either seizures (no differentiation was made between generalised or focal seizures) or focal neurology. However, two patients in the AIDS group had treatable intracranial disease, and only presented with headache or diffuse cerebral dysfunction, without focal neurology. The authors thus suggested that clinical signs remain useful for deciding whether urgent CT was appropriate. ${ }^{1}$

Rothman et al. attempted to correlate neurological signs and symptoms with new focal intracranial lesions in HIV-positive patients. The authors found that NOS was strongly associated with intracranial lesions; however, no differentiation was made between generalised and focal seizures. ${ }^{2}$

Holtzman et al. retrospectively reviewed 100 cases of NOS in HIV-positive patients. In this case series, mass lesions were found to be the most common cause of NOS in the HIV-positive population. Of note, however, is the fact that all the patients who presented with generalised seizures and a normal neurological examination either had meningitis, or no identifiable cause of their seizures could be identified. The authors further suggested that, despite the seizure type, a normal neurological examination implied a low probability of identifying an underlying cause for NOS. ${ }^{4}$

Modi et al. at the University of the Witwatersrand evaluated 37 HIV-infected patients with NOS with regards to seizure type, CD4 count and viral load. All patients for whom no identifiable cause for seizures could be determined presented with generalised seizures; however, $48 \%$ of the patients with focal brain lesions also presented with generalised seizures. The authors did not report whether the patients with focal brain lesions had co-existing focal neurology. ${ }^{5}$

The most specific research regarding generalised seizures in HIV-positive patients was done on a sample of 26 patients by Pesola et al. in 1998. They studied the aetiology of generalised NOS in patients with AIDS who presented at their emergency department. Six $(43 \%)$ of their patients necessitated emergency clinical management (requiring immediate hospitalisation and treatment); five were suffering from central nervous system (CNS) toxoplasmosis and one with CNS lymphoma. Notably, only two of these patients presented with focal neurology, and the authors therefore recommended emergency neuroimaging on all HIV-positive patients with generalised seizures, regardless of neurological examination findings. ${ }^{6}$ It is worth noting that the authors only investigated patients with a CD4 count
$<200$ cells $/ \mathrm{mm}^{3}$ (AIDS defining, according to the Centers for Disease Control and Prevention (CDC) staging system).

The incidence of NOS in the HIV-positive population has been reported to be as high as $17 \% \%^{7,8}$ (or even $20 \%$, as reported by Satishchandra et al., although selection bias might have been present because their hospital is an independent neurological referral centre). ${ }^{9}$ Furthermore, most of these patients present with generalised seizures, at a percentage as high as $71 \%{ }^{4,5,8,9,10,11}$ Obtaining emergency neuroimaging in so many of the patients could potentially overload emergency and radiology departments.

\section{Methods \\ Study design and setting}

We conducted a prospective descriptive observational study. Approval was obtained from the ethics committee of the Faculty of Health Sciences of the University of the Free State, as well as the clinical director of Kimberley Hospital Complex. Informed consent was obtained from either the patient or a family member. Data were collected from October 2014 to September 2015.

\section{Inclusion and exclusion criteria}

Consecutive HIV-positive patients $\geq 18$ years old who presented to Kimberley Hospital Complex emergency department within 24 hours of their first generalised seizures and who had a normal post-ictal neurological examination, were included.

Patients known to suffer from epilepsy, who had suffered any previous seizure (with or without secondary generalisation), who had any contra-indication to CT, or for whom there was clinical uncertainty, were excluded from the study.

\section{Measurement}

Patients who met the inclusion criteria for the study received a CT within 8 hours of clinical presentation, according to the Kimberley Hospital Rule. ${ }^{3}$

Patients with clinically suspected HIV infection received confirmatory laboratory testing with pre- and post-test counselling. If a patient's recent CD4 count was not known, it was obtained during admission.

The CD4 count results were divided into three groups, namely, CD 4 counts $<200$ cells $/ \mathrm{mm}^{3}$, $>200$ cells $/ \mathrm{mm}^{3} \leq 499$ cells $/ \mathrm{mm}^{3}$, and $>500$ cells $/ \mathrm{mm}^{3}$, in accordance with the CDC classification system.

Cranial CT was reported by a radiology registrar, with findings confirmed by a qualified radiologist; the differential diagnosis was completed on the datasheet. Decision to administer iodinated contrast was based on non-contrast CT findings. It was also noted whether the CT findings changed the emergency management (i.e. immediate hospitalisation and treatment). 


\section{Statistical analysis}

Descriptive statistics, namely median and ranges, were calculated for continuous data. Frequencies and percentages were calculated for categorical data.

\section{Results}

A total of 25 HIV-positive patients with generalised NOS and a normal post-ictal neurological examination were included in the study, of whom $15(60 \%)$ patients were male and $10(40 \%)$ were female; the median age was 40 years (minimum age 22 years and maximum age 56 years). Of the 25 patients, $19(76 \%)$ had had seizures that had been witnessed by medical personnel.

The CD4 counts for 2 patients were unknown, whilst 15 (65\%) patients had CD4 counts < 200 cells $/ \mathrm{mm}^{3}, 3(13 \%)$ patients had CD 4 counts $\geq 200 \leq 499$ cells $/ \mathrm{mm}^{3}$, and $5(22 \%)$ patients had CD4 counts $>500$ cells $/ \mathrm{mm}^{3}$ (Figure 1$)$.

CT was normal in $15(60 \%)$ patients and abnormal in $10(40 \%)$ patients; three $(12 \%)$ of the patients with an abnormal CT had intracranial lesions requiring urgent medical or surgical management. Two of these patients were diagnosed with ring-enhancing lesions and one with intracranial haemorrhage. All had CD4 counts $<200$ cells $/ \mathrm{mm}^{3}$. The emergency management did not have to be changed for the rest of the patients with abnormal CT findings. The predominant finding in these patients was

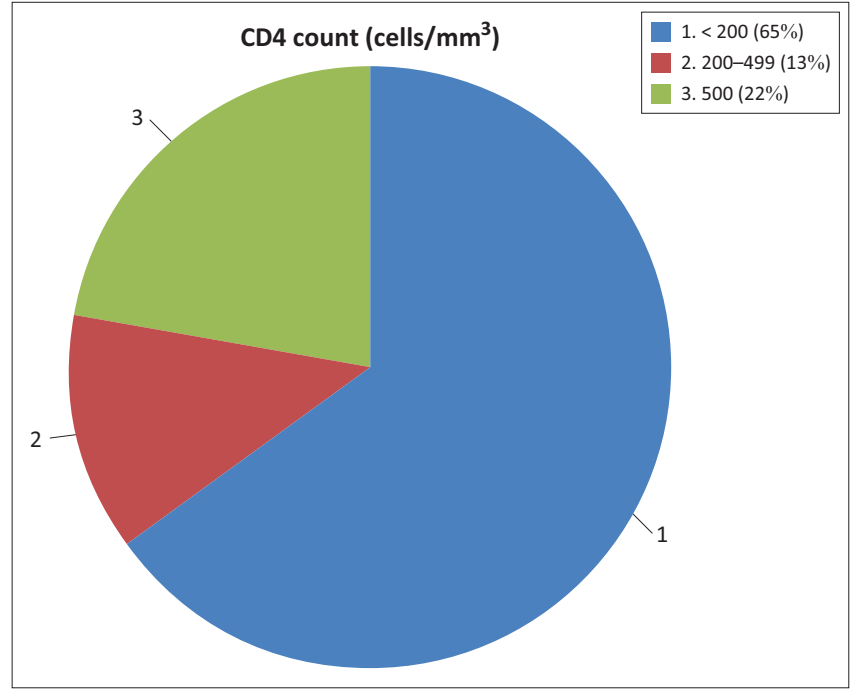

FIGURE 1: Percentage of patients in each CD4 count category according to the CDC CD4 count classification.

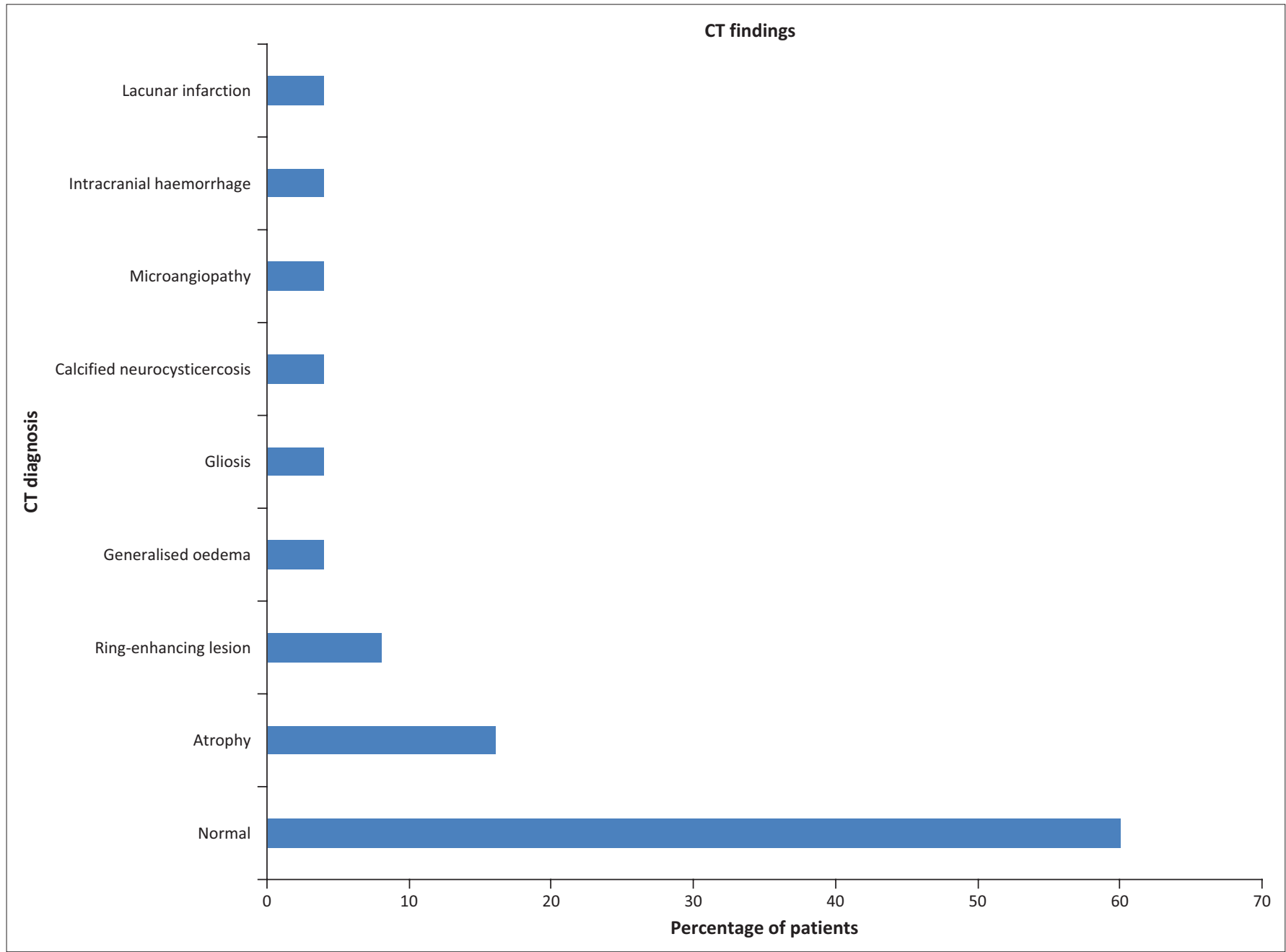

FIGURE 2: Computed tomography (CT) findings in our study population. 
generalised cerebral atrophy (which was defined as enlargement of intra- and extra-cerebral cerebrospinal fluid-containing spaces), which was diagnosed in four (16\%) patients (Figure 2). The results are summarised in Table 1.

\section{Discussion}

The results of cranial CT brought about a change in emergency care management in $12 \%$ of patients, which suggests that cranial CT has a role to play in the emergency management of the HIV-positive patient who presents with generalised NOS and a normal post-ictal neurological examination.

Most patients (90\%) with positive CT findings, and all patients for whom emergency clinical management was changed, had CD4 counts $<200$ cells $/ \mathrm{mm}^{3}$. Similar findings were noted in the study by Barber et al., where patients without focal neurology but with treatable intracranial pathology were in the AIDS-defined group. ${ }^{1}$ This suggests that a CD4 count $<200$ cells $/ \mathrm{mm}^{3}$ can be used as an indication for CT in patients presenting with generalised NOS and a normal post-ictal neurological examination, and that clinical neurological signs are indeed blurred in patients with severe immunosuppression. However, keeping in mind our small study population, larger prospective studies are needed to confirm this finding.

Our study demonstrated that seizures manifest late in the course of HIV infection, with $65.2 \%$ of our entire sample size in the AIDS-defining category $\left(\mathrm{CD} 4<200\right.$ cells $\left./ \mathrm{mm}^{3}\right)$ (Figure 1).
The most common positive CT finding in our study population was generalised cerebral atrophy, which is a known feature of HIV encephalopathy; this is also a common finding in other studies. ${ }^{1,2,4,6,9,10,11}$

\section{Limitations of the study}

The study was limited by the relatively small sample size. The frequent rotation of doctors through the Emergency Department made it difficult logistically to inform all clinical staff of our study and, consequently, not all eligible patients were included. However, considering that we only evaluated patients with generalised seizures, our study size compares well with that of Pesola et al. (who also only evaluated patients with generalised seizures), who had a sample size of 26 patients. ${ }^{6}$

Inaccuracies in seizure history were unavoidable, but we countered this by documenting on our datasheet whether the seizure had been witnessed by a me dical staff member.

\section{Conclusion}

Our study demonstrated that cranial CT changed emergency care management in a clinically relevant number of patients. Results also suggest that a CD4 count $<200$ cells $/ \mathrm{mm}^{3}$, in the presence of generalised NOS, could be used as an indication for emergency cranial CT. We suggest that emergency cranial CT be performed on all HIV-positive patients presenting with generalised NOS and a normal post-ictal neurological examination, especially if the CD4 count is $<200$ cells $/ \mathrm{mm}^{3}$.

TABLE 1: Summary of the findings in our study population.

\begin{tabular}{|c|c|c|c|c|}
\hline Patient & Age & Gender & CT findings & CD4 count (cells $/ \mathrm{mm}^{3}$ ) \\
\hline Patient 1 & 44 & $M$ & Gliosis & $<200$ \\
\hline Patient 2 & 30 & M & Normal & $200-499$ \\
\hline Patient 3 & 34 & $\mathrm{~F}$ & Generalised cerebral oedema & $<200$ \\
\hline Patient 4 & 41 & $\mathrm{~F}$ & Atrophy & $<200$ \\
\hline Patient 5 & 40 & M & Normal & $<200$ \\
\hline Patient 6 & 35 & $\mathrm{~F}$ & Ring-enhancing lesion & $<200$ \\
\hline Patient 7 & 40 & M & Atrophy & $<200$ \\
\hline Patient 8 & 40 & M & Normal & - \\
\hline Patient 9 & 30 & M & Normal & $<200$ \\
\hline Patient 10 & 36 & M & Atrophy & $<200$ \\
\hline Patient 11 & 41 & M & Normal & $<200$ \\
\hline Patient 12 & 42 & $\mathrm{~F}$ & Normal & - \\
\hline Patient 13 & 23 & M & Normal & $>500$ \\
\hline Patient 14 & 26 & $\mathrm{~F}$ & Normal & $<200$ \\
\hline Patient 15 & 38 & $\mathrm{~F}$ & Normal & $<200$ \\
\hline Patient 16 & 47 & $\mathrm{~F}$ & Normal & $>500$ \\
\hline Patient 17 & 39 & $\mathrm{~F}$ & Nodular calcified neurocysticercosis & $<200$ \\
\hline Patient 18 & 56 & M & Atrophy, lacunar infarction, microangiopathy & $>500$ \\
\hline Patient 19 & 41 & M & Ring-enhancing lesion & $<200$ \\
\hline Patient 20 & 23 & M & Normal & $200-499$ \\
\hline Patient 21 & 32 & $\mathrm{~F}$ & Normal & $<200$ \\
\hline Patient 22 & 22 & M & Normal & $>500$ \\
\hline Patient 23 & 54 & $\mathrm{~F}$ & Normal & $200-499$ \\
\hline Patient 24 & 44 & M & Normal & $>500$ \\
\hline Patient 25 & 50 & $M$ & Normal & $<200$ \\
\hline
\end{tabular}

$\mathrm{CT}$, computed tomography. 


\section{Acknowledgements}

We thank Mr C. van Rooyen, researcher, Department of Biostatistics, University of the Free State, for help with statistical analysis.

\section{Competing interests}

The authors declare that they have no financial or personal relationship that may have inappropriately influenced them in writing this article.

\section{Authors' contributions}

C.V.Z. was the project leader. C.V.Z., D.H. and L.K. were responsible for protocol planning. L.K. and V.S. helped with data collection. C.V.Z. was the primary author of the manuscript and D.H. and V.S. helped with manuscript editing.

\section{References}

1. Barber C, Rowlands P, McCarty M, Choudhri A, Stevens J. Clinical utility of cranial CT in HIV positive and AIDS patients with neurological disease. Clin Radiol. 1990;164-165.
2. Rothman R, Keyl P, McArthur J, Beauchamp Jr N, Danyluk T, Kelen G. A decision guideline for emergency department utilization of noncontrast head computed tomography in HIV-infected patients. Acad Emerg Med. 1999;6:1010-1019.

3. Bezuidenhout A, Hurter D, Maydell A, et al. The Kimberley Hospital Rule (KHR) for urgent computed tomography of the brain in a resource-limited environment. S Afr Med J. 2013;103:646-651. http://dx.doi.org/10.7196/SA MJ.6876

4. Holtzman D, Kaku D, So Y. New-onset seizures associated with human immunodeficiency virus infection: Causation and clinical features in 100 cases. Am J Med. 1989;87:173-177.

5. Modi M, Mochan A, Modi G. New onset seizures in HIV - seizure semiology, CD4 counts, and viral loads. Epilepsia. 2009;50:1266-1269. http://dx.doi.org/10.1111/ j.1528-1167.2008.01942.x

6. Pesola G, Westfal R. New-onset generalized seizures in patients with AIDS presenting to an emergency department. Acad Emerg Med. 1998;5: 905-911.

7. Modi G, Modi M, Martinus I, Vangu M. New onset seizures in HIV-infected patients without intracranial mass lesions or meningitis - a clinical, radiological and SPECT scan study. J Neurol Sci. 2002;202:29-34.

8. Pascual-Sedano B, Iranzo A, Martí-Fàbregas J, et al. Prospective study of new onset seizures in patients with human immunodeficiency virus infection. Arch Neurol. 1999;56:609-612.

9. Satishchandra P, Sinha S. Seizures in HIV-seropositive individuals: NIMHANS experience and review. Epilepsia. 2008;49:33-41. http://dx.doi.org/10.1111/ j.1528-1167.2008.01754.x

10. Kellinghaus $C$, Engbring $C$, Kovac $S$, et al. Frequency of seizures and epilepsy in neurological HIV-infected patients. Seizure. 2008;17:27-33. http://dx.doi.org/1 0.1016/j.seizure.2007.05.017

11. Garg R. HIV infection and seizures. Postgrad Med J. 1999;75:387-390. 